some attractive biological characteristics as a drug target. First, its site of action within the central death machinery may provide a target for specific inhibition of cell death. Second, its low basal levels in most tissues may minimize the possibility of untoward effects in nontarget organs. Third, the fact that Bnip3 is induced in response to hypoxia suggests that there is a temporal window, prior to significant Bnip3 accumulation and cell death, during which treatment could be beneficially instituted. Despite these characteristics, significant logistical hurdles exist in designing a practical pharmacological approach to inhibit this intracellular protein.

\section{Acknowledgments}

We thank Nikolaos G. Frangogiannis, Baylor College of Medicine, for helpful discussions. R.N. Kitsis is supported by NIH grants R01HL60665, R01HL61550, and R01HL80607, and the Dr. Gerald and Myra Dorros Chair in Cardiovascular Disease of the Albert Einstein College of Medicine. R.S. Whelan is supported by NIH grant T32AG23475.

Address correspondence to: Richard N. Kitsis, Albert Einstein College of Medicine, 1300 Morris Park Avenue, Bronx, New York 10461, USA. Phone: (718) 430-2609; Fax: (718) 4308989; E-mail: kitsis@aecom.yu.edu.
1. Kajstura, J., et al. 1996. Apoptotic and necrotic myocyte cell deaths are independent contributing variables of infarct size in rats. Lab. Invest. 74:86-107.

2. Sutton, M.G., and Sharpe, N. 2000. Left ventricular remodeling after myocardial infarction: pathophysiology and therapy. Circulation. 101:2981-2988.

3. Frangogiannis, N.G. 2006. The mechanistic basis of infarct healing. Antioxid. Redox Signal. 8:1907-1939.

4. Anversa, P., Beghi, C., Kikkawa, Y., and Olivetti, G. 1985. Myocardial response to infarction in the rat. Morphometric measurement of infarct size and myocyte cellular hypertrophy. Am. J. Pathol. 118:484-492.

5. Mani, K., and Kitsis, R.N. 2003. Myocyte apoptosis: programming ventricular remodeling. J. Am. Coll. Cardiol. 41:761-764.

6. Yaoita, H., Ogawa, K., Maehara, K., and Maruyama, Y. 1998. Attenuation of ischemia/reperfusion injury in rats by a caspase inhibitor. Circulation. 97:276-281.

7. Matsui, T., et al. 2001. Akt activation preserves cardiac function and prevents injury after transient cardiac ischemia in vivo. Circulation. 104:330-335.

8. Odashima, M., et al. 2007. Inhibition of endogenous Mst 1 prevents apoptosis and cardiac dysfunction without affecting cardiac hypertrophy after myocardial infarction. Circ. Res. 100:1344-1352.

9. Danial, N.N., and Korsmeyer, S.J. 2004. Cell death: critical control points. Cell. 116:205-219.

10. Adams, J.M., and Cory, S. 2007. Bcl-2-regulated apoptosis: mechanism and therapeutic potential. Curr. Opin. Immunol. In press.

11. Willis, S.N., et al. 2007. Apoptosis initiated when $\mathrm{BH} 3$ ligands engage multiple $\mathrm{Bcl}-2$ homologs, not Bax or Bak. Science. 315:856-859.

12. Kim, H., et al. 2006. Hierarchical regulation of mitochondrion-dependent apoptosis by BCL-2 subfamilies. Nat. Cell Biol. 8:1348-1358.

13. Yasuda, M., Theodorakis, P., Subramanian, T., and Chinnadurai, G. 1998. Adenovirus E1B-19K/BCL-2 interacting protein $\mathrm{BNIP} 3$ contains a $\mathrm{BH} 3$ domain and a mitochondrial targeting sequence. J. Biol. Chem. 273:12415-12421.

14. Ray, R, et al. 2000. BNIP3 heterodimerizes with Bcl-2/ $\mathrm{Bcl}-\mathrm{X}(\mathrm{L})$ and induces cell death independent of a Bcl-2 homology 3 (BH3) domain at both mitochondrial and nonmitochondrial sites. J. Biol. Chem. 275:1439-1448.

15. Bruick, R.K. 2000. Expression of the gene encoding the proapoptotic Nip3 protein is induced by hypoxia. Proc. Natl. Acad. Sci. U. S. A. 97:9082-9087.

16. Chen, G., et al. 1997. The E1B 19K/Bcl-2-binding protein Nip3 is a dimeric mitochondrial protein that activates apoptosis. J. Exp. Med. 186:1975-1983.

17. Vande Velde, C., et al. 2000. BNIP3 and genetic control of necrosis-like cell death through the mitochondrial permeability transition pore. Mol. Cell. Biol. 20:5454-5468.

18. Regula, K.M., Ens, K., and Kirshenbaum, L.A. 2002. Inducible expression of BNIP3 provokes mitochondrial defects and hypoxia-mediated cell death of ventricular myocytes. Circ. Res. 91:226-231

19. Kubasiak, L.A., Hernandez, O.M., Bishopric, N.H., and Webster, K.A. 2002. Hypoxia and acidosis activate cardiac myocyte death through the Bcl-2 family protein BNIP3. Proc. Natl. Acad. Sci. U. S. A. 99:12825-12830.

20. Hamacher-Brady, A., Brady, N.R., Gottlieb, R.A., and Gustafsson, A.B. 2006. Autophagy as a protective response to Bnip3-mediated apoptotic signaling in the heart. Autophagy. 2:307-309.

21. Kubli, D.A., Ycaza, J.E., and Gustafsson, A.B. 2007. Bnip3 mediates mitochondrial dysfunction and cell death through Bax and Bak. Biochem. J. 405:407-415.

22. Diwan, A., et al. 2007. Inhibition of ischemic cardiomyocyte apoptosis through targeted ablation of Bnip3 restrains postinfarction remodeling in mice. J. Clin. Invest. 117:2825-2833. doi:10.1172/JCI32490.

23. Toth, A., et al. 2006. Targeted deletion of Puma attenuates cardiomyocyte death and improves cardiac function during ischemia-reperfusion. Am. J. Physiol. Heart Circ. Physiol. 291:H52-H60.

24. Guo, K., et al. 2001. Hypoxia induces the expression of the pro-apoptotic gene BNIP3. Cell Death Differ. 8:367-376.

25. Sowter, H.M., Ratcliffe, P.J., Watson, P., Greenberg, A.H., and Harris, A.L. 2001. HIF-1-dependent regulation of hypoxic induction of the cell death factors BNIP3 and NIX in human tumors. Cancer Res. 61:6669-6673.

\title{
Obesity and the $\beta$ cell: lessons from leptin
}

\author{
Kevin D. Niswender ${ }^{1}$ and Mark A. Magnuson²
}

\author{
${ }^{1}$ Tennessee Valley Healthcare System and Department of Medicine and ${ }^{2}$ Center for Stem Cell Biology and \\ Department of Molecular Physiology and Biophysics, Vanderbilt University School of Medicine, Nashville, Tennessee, USA.
}

\begin{abstract}
In this issue of the JCI, Morioka et al. report on mice with a whole-pancreas knockout of the leptin receptor that exhibit improved glucose tolerance due to enhanced insulin secretion (see the related article beginning on page 2860). At first glance, their findings are very different from those reported in another recent study in which $\beta$ cell-specific and hypothalamic knockout of the same gene caused obesity and impaired $\beta$ cell function. The differences, which are understandable when one considers the body weights of the animals studied, provide new insight into the links among insulin, leptin action, and $\beta$ cell function.
\end{abstract}

Nonstandard abbreviations used: $K_{\text {ATP }}$ channel, ATP-sensitive potassium channel; Pdx1, pancreatic and duodenal homeobox 1 .

Conflict of interest: Kevin D. Niswender has received honoraria and/or research funding from Merck \& Co. and Novo Nordisk.

Citation for this article: J. Clin. Invest. 117:2753-2756 (2007). doi:10.1172/JCI33528.
The prevalence of both obesity and type 2 diabetes are increasing at an alarming rate. Clearly, an improved understanding of the mechanisms involved in energy homeostasis will be required to halt these epidemics. In 1994, the cloning of the peptide hormone leptin, an adipocyte-derived factor secreted in proportion to body fat, opened new doors for exploring the molecular mechanisms underpinning energy homeostasis (1). However, despite an avalanche of new knowledge gained since then, many fundamental questions remain unanswered, including how systems regulating energy homeostasis interface with those that regulate glucose homeostasis.

\section{Leptin and glucose homeostasis}

Mice and humans that are deficient in either leptin (in the case of $o b / o b$ mice) or the leptin receptor ( $d b / d b$ mice) not only develop obesity, but become both insulin resistant and glucose intolerant and are at high risk to develop diabetes (1-3). The pro- 


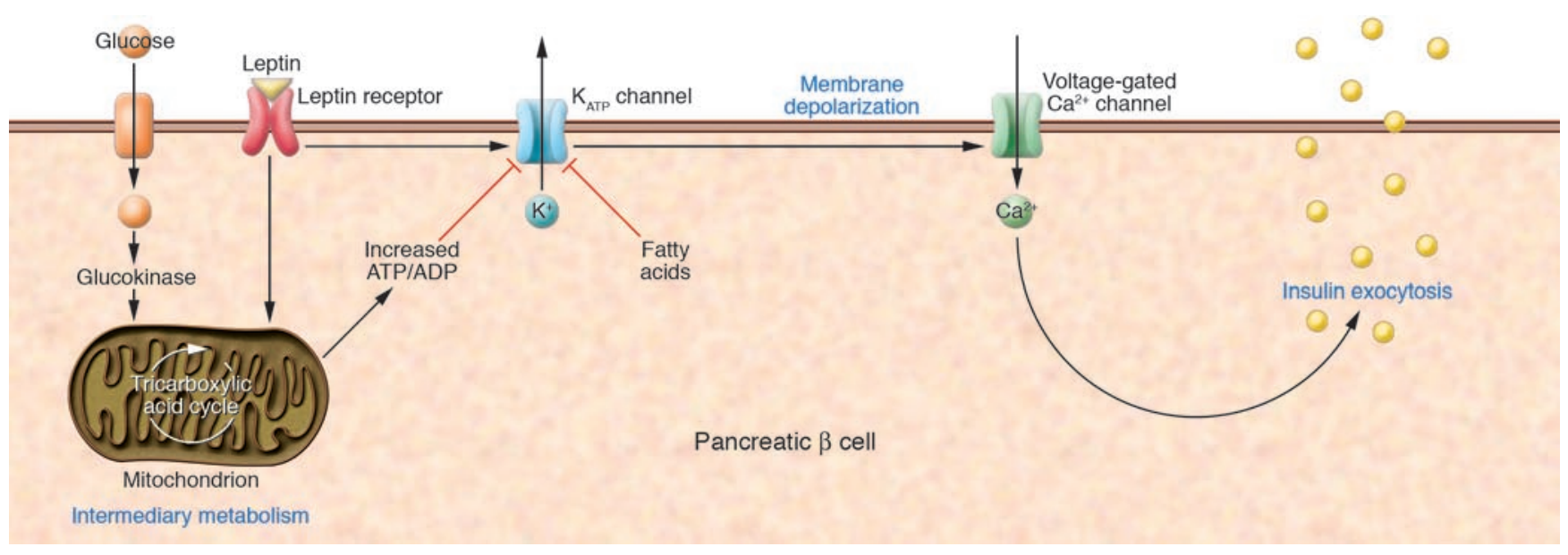

Figure 1

Effects of leptin on the pancreatic $\beta$ cell. The secretion of insulin is a complex, multistep process. The $\beta$ cell senses nutrient availability, including that of glucose, amino acids, and fatty acids, through the metabolism of these molecules. An increase in the ATP/ADP ratio stimulates closure of the $\mathrm{K}_{\text {ATP }}$ channel, thereby causing depolarization of the plasma membrane, activation of a voltage-dependent calcium channel, and insulin exocytosis. The study by Morioka et al. (5) in this issue of the $\mathrm{JCl}$ shows that, in the context of overnutrition, leptin attenuates insulin secretion by the $\beta$ cell. First, leptin appears to function to maintain the patency of the $\mathrm{K}_{\text {ATP }}$ channel, thereby hyperpolarizing the $\beta$ cell plasma membrane. This could occur either by enhancing channel activity or by rendering the channel less sensitive to changes in the ATP/ADP ratio. Second, leptin may play a role in maintaining flux through key metabolic pathways of intermediary metabolism by assuring the proper allosteric and transcriptional regulation of key metabolic enzymes. If so, impaired leptin signaling in the $\beta$ cell could lead to an enhanced susceptibility to the negative effects of overnutrition, thereby causing an impairment of insulin secretion.

found insulin resistance and glucose intolerance that characterize leptin deficiency are, intriguingly, to some degree independent of body weight. Indeed, treatment of leptin-deficient animals with leptin restores glucose homeostasis independent of weight loss (4), which suggests that leptin may act directly on pancreatic $\beta$ cells to affect their function. Toward that end, in this issue of the JCI, Morioka and coworkers describe a pancreas-wide knockout of the leptin receptor in mice (5). Interestingly, the principal phenotype of their mice, namely improved glucose tolerance, is in apparent contradiction to that reported in a recent study by Covey et al. (6), who also utilized a Cre-loxP strategy to assess the effect of a combined $\beta$ cell and partial hypothalamic knockout of the leptin receptor. Covey et al. concluded that the loss of leptin signaling in the pancreatic $\beta$ cell causes impaired $\beta$ cell function, although their animals, like those studied by Morioka et al., exhibited fasting hypoglycemia relative to the controls due to insulin hypersecretion.

\section{Weighty differences in experimental design and outcome}

To attempt to reconcile these two very similar studies, it is vital to have an understanding of the biology of both the floxed leptin receptor alleles and the Cre recombinase driver mice that were used. Morioka et al. (5) used a conditional allele that removes exon 1 from the leptin receptor gene (7), whereas that used by Covey et al. (6) removes exon 17 (8). Cre recombinase causes a total gene ablation of the former allele, whereas a frameshift mutation of the leptin receptor occurs in the latter situation, resulting in a receptor protein that lacks both Tyr985 and Tyr 1138 - sites of JAK-mediated phosphorylation necessary for leptin-stimulated STAT phosphorylation (8). While total gene ablations of proteins that provide scaffolding functions may sometimes generate misleading phenotypes, this is unlikely to be the case here. Rather, the different phenotypes observed are far more likely to be due to the use of different $C r e$ driver lines, which led to the absence of the leptin receptor in overlapping but different cell types and tissues. Although the Cre driver lines used by both groups are state of the art, in neither case does the gene deletion occur only in pancreatic $\beta$ cells.

Covey et al. (6) used the well-known rat insulin 2 promoter (RIP) Cre driver line (9) to generate a combined $\beta$ cell and partial mediobasal hypothalamic knockout of the leptin receptor. On the other hand, Morioka et al. (5) used a pancreatic and duodenal homeobox 1-Cre (Pdx1-Cre) transgene to disrupt expression of the leptin recep- tor in the pancreas without affecting its expression in the brain. However, it should be noted that $P d x 1$ is broadly expressed in the posterior foregut during development (10-12). Thus, the use of a Pdx1-Cre transgene by Morioka et al. may have also deleted expression of the leptin receptor in cells that secrete glucagon, glucagon-like peptide 1 (GLP-1), glucose-dependent insulinotropic peptide (GIP), ghrelin, and others, all of which have well-known roles in glucose homeostasis. Nonetheless, even if leptin signaling was disrupted in other cell types, the findings are almost certainly due to changes in $\beta$ cell function. Comparison of the two studies suggests that deletion of the leptin receptor in the hypothalamus of the mice utilized by Covey et al. (6) is a more significant factor than initially thought. While these investigators reasonably attempted to control for this possibility by comparing $\beta$ cell function in weightmatched animals, an experiment performed by Morioka et al. (5) becomes key for reconciling the observed phenotypic differences. They tested the effect of a high-fat diet on mice lacking leptin receptors only in the pancreas and found that as the mice developed diet-induced obesity, the phenotype of these animals shifted from one of improved to impaired $\beta$ cell function, relative to that of mice that had intact leptin receptors 


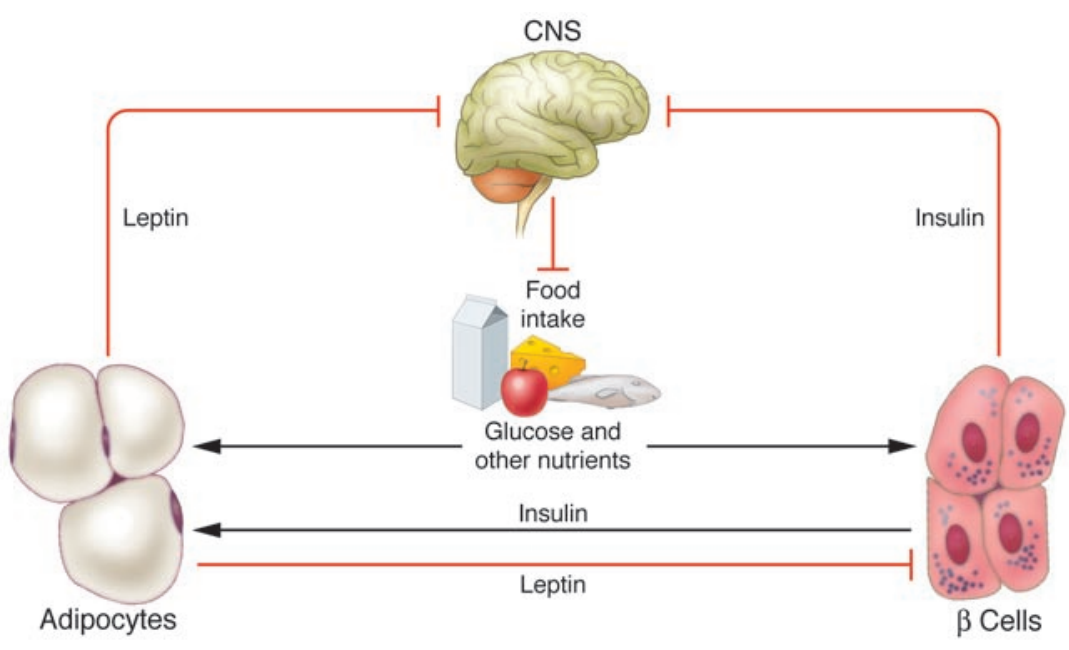

\section{Figure 2}

Homeostatic feedback loops affecting energy homeostasis and glucose homeostasis. Leptin and insulin are both secreted in proportion to energy availability. Whereas leptin secretion is indicative of adipose mass and thus is more chronic in nature, insulin secretion reflects both acute and chronic nutritional status. The findings of Morioka et al. (5) validate the existence of an adipose tissue-islet endocrine feedback loop. Insulin is both potently lipogenic and functions in the CNS to reduce nutrient intake. Leptin also acts on the CNS to reduce nutrient intake and directly on $\beta$ cells in lean animals to inhibit insulin secretion. The findings of both Morioka et al. (5) and Covey et al. (6) suggest that as body weight increases, leptin signaling protects the $\beta$ cell from the adverse effects of overnutrition. Thus, glucose and energy homeostasis should both be considered in a very broad manner that simultaneously takes into account the effects of glucose, insulin, and leptin in multiple tissues.

in their $\beta$ cells. Thus, it now appears that because the genetically engineered mice made by Covey et al. were heavier than littermate controls, they exhibited impaired $\beta$ cell function. Therefore, given the model proposed below, obese animals that lack leptin signaling in their $\beta$ cells will have decreased $\beta$ cell function, compared with weight-matched controls. Covey et al. (6) simply achieved obesity through a genetically induced impairment of leptin signaling in the hypothalamus instead of by feeding a high-fat diet, as did Morioka et al. (5).

\section{The pancreatic $\beta$ cell \\ and metabolic sensing}

The pancreatic $\beta$ cell is an exquisite metabolic energy sensor. Although glucose is the principal insulin secretagogue, amino acids, fatty acids, and a number of hormones (including both insulin and leptin) and neurotransmitters also affect the amount of insulin that is secreted (Figure 1). The intracellular mechanisms that couple these various stimuli to insulin secretion are both complex and highly interdependent. For instance, the ATP-sensitive potassium $\left(\mathrm{K}_{\mathrm{ATP}}\right)$ channel, which determines $\beta$ cell membrane potential, also serves to couple intracellular metabolism to plasma membrane poten- tial in the $\beta$ cell. This channel is sensitive to changes in the ATP/ADP ratio, PI3K signaling (mediated either by insulin [ref. 13] or leptin [ref. 14]), and long-chain fatty acids or their derivatives $(15,16)$. Closure of this channel leads to membrane depolarization, activation of a voltage-dependent calcium channel, influx of calcium, and the initiation of insulin secretion.

Leptin induces $\beta$ cell hyperpolarization by activating insulin-like signal transduction - a phenomenon referred to as cross-talk (17) - which, by activating the $\mathrm{K}_{\mathrm{ATP}}$ channel, inhibits insulin secretion. Cross-talk between leptin and insulin signaling is a more complex process than it may first appear, especially given a number of recent findings $(14,18)$. Nonetheless, the absence of leptin signaling in $\beta$ cells of lean mice is predicted to improve basal insulin secretion by removing this hyperpolarizing force. While this prediction is confirmed by the findings of both groups $(5,6)$, the $K_{\text {ATP }}$ channel-dependent membrane effects of leptin are not the end of the story (Figure 1).

As we now know, consumption of a highfat diet, or overnutrition, in either humans or rodents causes metabolic alterations that increase the risk of developing diabetes. Many different names have been coined to describe these alterations (e.g., insulin resistance, glucotoxicity, lipotoxicity, oxidative stress, and mitochondrial dysfunction). Whatever term one prefers, nutrient excess leads to an uncoupling of the sensory secretion mechanisms in the $\beta$ cell. Intermediary metabolism serves as the vital link by enabling the $\beta$ cell to sum and integrate a plethora of different metabolic stimuli. For example, glucose oxidation, fatty acid oxidation, and long-chain fatty acyl CoA synthesis are so interlinked that they oscillate in synchrony (19). Inhibition of key control steps in these signaling pathways, as occurs in the setting of overnutrition, impairs insulin secretion. It has long been thought that a vital function of leptin at the cellular level is to maintain the ebb and flow of cellular metabolic information by preventing the accumulation of fat in the wrong places, such as $\beta$ cells, where it leads to cellular dysfunction (20). The findings of both Morioka et al. (5) and Covey et al. (6), by indicating a vital function for leptin in $\beta$ cells exposed to overnutrition, support this notion.

\section{Adiposity and $\beta$ cell function: an integrated view}

Not only do the findings of both Morioka et al. (5) and Covey et al. (6) support a role for leptin signaling in the pancreatic $\beta$ cell, they also have broader implications for understanding energy homeostasis. Since (a) leptin is secreted in direct proportion to adipose mass; (b) insulin is potently lipogenic; and (c) leptin has a restraining effect on the $\beta$ cell, the new findings validate the existence of an adipose tissue-islet feedback loop in which insulin secretion by the $\beta$ cell is inversely related to body fat (Figure 2). Moreover, these findings add additional complexity to current models of energy homeostasis that will require further exploration and validation. Indeed, it is becoming clear that one must conceptualize energy homeostasis in a very broad manner that simultaneously considers the effects of glucose, insulin, and leptin in multiple tissues.

Finally, these findings also highlight several long-standing questions, such as, why doesn't obesity always cause diabetes? For any biological system this important and complex, there will certainly be other physiological mediators whose function is to further integrate the signals generated principally by glucose, insulin, and leptin. However, to understand what these mediators are and how they work, the use 
of Cre-expressing mice that express this enzyme in a strictly $\beta$ cell-specific manner will be essential. Indeed, considering that efforts are currently underway to generate conditional alleles for virtually all genes, the Cre-loxP strategy will be a cornerstone technology for understanding energy homeostasis in the mouse. However, certain lines of mice, including the B6. Cg- $\mathrm{Tg}$ (Ins2-Cre) $25 \mathrm{Mgn} / \mathrm{J}$ animals we generated nearly ten years ago (9) and that were used by Covey et al., need to be supplemented by more robust models that are free of some of the flaws that have been so aptly demonstrated here and elsewhere.

\section{Acknowledgments}

The authors are supported by NIH grants DK64857 and DK69927 (to K.D. Niswender) and DK42502 and DK72473 (to M.A. Magnuson).

Address correspondence to: Mark A. Magnuson, Center for Stem Cell Biology and Department of Molecular Physiology and Biophysics, Vanderbilt University School of Medicine, 802 Light Hall, 21st Avenue South at Garland Avenue, Nashville, Tennessee 37232-0255, USA. Phone: (615)
322-7006; Fax: (615) 322-7236; E-mail: mark.magnuson@vanderbilt.edu.

1. Zhang, Y., et al. 1994. Positional cloning of the mouse obese gene and its human homologue. Nature. 372:425-432.

2. Lee, G.H., et al. 1996. Abnormal splicing of the leptin receptor in diabetic mice. Nature. 379:632-635.

3. Sadaf Farooqi, I., et al. 2002. Beneficial effects of leptin on obesity, $\mathrm{T}$ cell hyporesponsiveness, and neuroendocrine/metabolic dysfunction of human congenital leptin deficiency. J. Clin. Invest. 110:1093-1103. doi:10.1172/JCI200215693.

4. Harris, R.B., et al. 1998. A leptin dose-response study in obese (ob/ob) and lean (+/?) mice. Endocrinology. 139:8-19.

5. Morioka, T., et al. 2007. Disruption of leptin receptor expression in the pancreas directly affects $\beta$ cell growth and function in mice. J. Clin. Invest. 117:2860-2868. doi:10.1172/JCI30910.

6. Covey, S.D., et al. 2006. The pancreatic beta cell is a key site for mediating the effects of leptin on glucose homeostasis. Cell Metab. 4:291-302.

7. Cohen, P., et al. 2001. Selective deletion of leptin receptor in neurons leads to obesity. J. Clin. Invest. 108:1113-1121. doi:10.1172/JCI200113914.

8. McMinn, J.E., et al. 2004. An allelic series for the leptin receptor gene generated by CRE and FLP recombinase. Mamm. Genome. 15:677-685.

9. Postic, C., et al. 1999. Dual roles for glucokinase in glucose homeostasis as determined by liver and pancreatic beta cell-specific gene knock-outs using Cre recombinase. J. Biol. Chem. 274:305-315.

10. Guz, Y., et al. 1995. Expression of murine STF-1, a putative insulin gene transcription factor, in beta cells of pancreas, duodenal epithelium and pancreatic exocrine and endocrine progenitors during ontogeny. Development. 121:11-18.

11. Jonsson, J., Carlsson, L., Edlund, T., and Edlund, H. 1994. Insulin-promoter-factor 1 is required for pancreas development in mice. Nature. 371:606-609.

12. Offield, M.F., et al. 1996. PDX-1 is required for pancreatic outgrowth and differentiation of the rostral duodenum. Development. 122:983-995.

13. Aspinwall, C.A., et al. 2000. Roles of insulin receptor substrate-1, phosphatidylinositol 3-kinase, and release of intracellular $\mathrm{Ca} 2+$ stores in insulin-stimulated insulin secretion in beta-cells. J. Biol. Chem. 275:22331-22338.

14. Harvey, J., et al. 2000. Essential role of phosphoinositide 3-kinase in leptin-induced K(ATP) channel activation in the rat CRI-G1 insulinoma cell line. J. Biol. Chem. 275:4660-4669.

15. Buschard, K., et al. 2006. C16:0 sulfatide inhibits insulin secretion in rat beta-cells by reducing the sensitivity of KATP channels to ATP inhibition. Diabetes. 55:2826-2834.

16. Tarasov, A., Dusonchet, J., and Ashcroft, F. 2004. Metabolic regulation of the pancreatic beta-cell ATP-sensitive K+ channel: a pas de deux. Diabetes. 53(Suppl. 3):S113-S122.

17. Niswender, K.D., et al. 2003. Insulin activation of phosphatidylinositol 3-kinase in the hypothalamic arcuate nucleus: a key mediator of insulin-induced anorexia. Diabetes. 52:227-231.

18. Ning, K., et al. 2006. A novel leptin signalling pathway via PTEN inhibition in hypothalamic cell lines and pancreatic beta-cells. EMBOJ. 25:2377-2387.

19. Prentki, M., Joly, E., El-Assaad, W., and Roduit, R. 2002. Malonyl-CoA signaling, lipid partitioning, and glucolipotoxicity: role in beta-cell adaptation and failure in the etiology of diabetes. Diabetes. 51(Suppl. 3):S405-S413.

20. Unger, R.H. 2003. The physiology of cellular liporegulation. Annu. Rev. Physiol. 65:333-347.

\title{
Role for HLA in susceptibility to infectious mononucleosis
}

\author{
Paul J. Farrell
}

Department of Virology, Imperial College London, London, United Kingdom.

\begin{abstract}
Factors involved in determining whether infectious mononucleosis occurs after primary EBV infection may include age, dose of virus received, and various genetic markers. A study by McAulay and colleagues reported in this issue of the JCI shows that the presence of certain HLA class I alleles correlates with the incidence and severity of infectious mononucleosis (see the related article beginning on page 3042). These same HLA alleles are also risk factors for EBV-associated Hodgkin lymphoma (HL), supporting recent epidemiology that indicates that a history of infectious mononucleosis predisposes to HL. Recent studies suggest that an EBV vaccine might help to prevent infectious mononucleosis, and further development of this should now be considered.
\end{abstract}

Nonstandard abbreviations used: EBNA, EpsteinBarr nuclear antigen; HL, Hodgkin lymphoma; IM, infectious mononucleosis; $L M P$, latent viral protein.

Conflict of interest: The author has declared that no conflict of interest exists.

Citation for this article: $J$. Clin. Invest. 117:2756-2758 (2007). doi:10.1172/JCI33563.
Over $90 \%$ of the world's population become infected by EBV in their lifetime (1), and EBV is one of the best understood herpesviruses at the molecular level, but there are still some remarkable gaps in our knowledge about the details of natural EBV infection. Primary EBV infection was shown many years ago to be the main cause of infectious mononucleosis (IM). EBV mainly infects B lymphocytes, and the current model of in vivo infection (1-3) suggests that the purpose of the various Epstein-Barr nuclear antigen (EBNA) and latent viral protein $(L M P)$ genes in $\mathrm{EBV}$ is to ensure survival of infected B cells so that they can transit into the long-lived memory B cell population, in which the virus is thought to persist. In this respect, the viral strategy is analogous to that of other herpesviruses, which are characterized by persistence in a latent state in a certain cell type for the lifetime of the infected host. Replicating EBV can be found in antibodyproducing plasma cells (4), which result from the end-stage of $B$ cell differentiation, indicating that reactivation of EBV and 